\title{
Diagênese de arenitos da Formação Tatuí no estado de São Paulo
}

\author{
Nara Lúcia Barbosa-Gimenez ${ }^{1}$ \& Maria Rita Caetano-Chang ${ }^{2}$
}

\begin{abstract}
Resumo A análise petrológica de arenitos da Formação Tatuí, por meio de métodos de microscopia óptica e catodoluminescência, permitiu o entendimento da evolução diagenética a que foram submetidos esses depósitos. Neste estudo, foram utilizadas amostras de testemunhos de sondagem de poços perfurados no estado de São Paulo, além de algumas coletadas em afloramentos. A história diagenética dos arenitos da unidade desenvolveu-se nos regimes eodiagenético e mesodiagenético; os arenitos próximos à superfície foram submetidos também ao regime telodiagenético. O regime eodiagenético foi marcado por substituição de bioclastos (carapaças calcárias de bivalves), dissolução de minerais instáveis e precipitação de cimentos de calcita microcristalina, pirita, feldspato potássico e óxidos de ferro. Durante a mesodiagênese, o soterramento e a compactação mecânica tornaram-se mais efetivos, desencadeando várias fases diagenéticas, representadas por crescimento secundário de quartzo e plagioclásios, cimentação por calcita poiquilotópica e em mosaicos, cimentação por dolomita (pura, ferrosa e anquerita), dissolução de calcita e feldspato, precipitação de caulinita e calcita tardia, albitização de feldspatos, precipitação de zeólitas, cimentação por anidrita,anatásio e sílica. Os arenitos submetidos ao ambiente telodiagenético apresentam quantidades razoáveis de cimento ferruginoso e caulinita, feições de dissolução em feldspatos e ausência de cimento carbonático.
\end{abstract}

Palavras-chave: Diagênese de arenitos; Formação Tatuí; Permiano da Bacia do Paraná.

\begin{abstract}
Diagenesis of Tatuí Formation sandstones in São Paulo state, Brazil. Tatuí Formation represents the Permian post-glacial sedimentary rocks of the Paraná Basin, in São Paulo state. The unit is correlated to Palermo and Rio Bonito formations (Guatá Group) found in southern states of Paraná, Santa Catarina and Rio Grande do Sul. Petrologic analysis of Tatuí Formation sandstones using optical microscopy and catodoluminescence provided the understanding of their diagenetic evolution. These studies were carried on samples from well cores and outcrops in São Paulo State. During the eogenetic regime the sediments undergone processes such as replacement of bioclasts (calcareous shells of bivalves), unstable minerals dissolution and cement precipitation of microcrystalline calcite, pirite, K-feldspar, and Fe-oxides. Mesogenetic regime was characterized by mechanical compaction, quartz and plagioclase overgrowths, poikilotopic and mosaic calcite cementation, dolomite through ankerite cementation, followed by calcite and feldspar dissolution, precipitation of kaolinite and late calcite, albitization of feldspars, precipitation of zeolite, anhydrite, anatase and silica. Sandstones submitted to telodiagenesis show high ferruginous and kaolinite cement, feldspar dissolution and absence of calcite cement.
\end{abstract}

Keywords: Sandstone diagenesis; Tatuí Formation; Permian of Paraná Basin.

INTRODUÇ̃̃O A Formação Tatuí representa o registro da sedimentação pós-glacial na porção nordeste da Bacia Sedimentar do Paraná, como parte da sequência sedimentar do Grupo Tubarão, de idade Permiana. Esta unidade correlaciona-se às formações Palermo e Rio Bonito (Grupo Guatá), que representam o início do ciclo pós-glacial nos estados do Paraná, Santa Catarina e Rio Grande do Sul.

Nas décadas de 1970 e 1980, a Formação Tatuí foi alvo de vários trabalhos, em geral com ênfase à estratigrafia e à condição pós-glacial de deposição dos sedimentos (Soares 1972, Fúlfaro et al. 1984, Stevaux et al. 1986, Cabral Junior et al. 1988). No entanto, estudos sobre a petrografia e particularmente sobre a diagênese de suas rochas, como os de Barbosa-Gimenez (1996) e Barbosa-Gimenez \& Caetano-Chang (1998), não têm sido documentados.

Segundo Fúlfaro et al. (1984) e Stevaux et al. (1986), graças a movimentos verticais na borda norte da bacia (Flexura de Goiânia), desenvolveram-se, nessa área, complexos deltaicos que foram progressivamente afogados por evento marinho transgressivo. Para Stevaux et al. (1986), os arenitos da Formação Tatuí foram depositados principalmente em ambiente costeiro, em barras litorâneas e plataformais de sistemas flúviodeltaicos, e em cunhas clásticas do tipo fan-deltas. Ao final da sedimentação da unidade, já em ambiente de plataforma, ocorreu o clímax da ingressão marinha na Bacia do Paraná (Northfleet et al. 1969).

A Formação Tatuí é constituída predominantemente por pelitos, formando espessas camadas de siltitos argilosos e intercalando, subordinadamente, cama- 
das de arenitos, calcários, folhelhos e sílex. Embora de ocorrência subordinada, os arenitos podem ser encontrados em toda extensão da Formação Tatuí, distribuindo-se desde a borda atual até porções mais centrais da bacia em São Paulo, e são portadores de valiosas informações para o entendimento da história diagenética da unidade. Estudos petrográficos desenvolvidos por Barbosa-Gimenez (1996) e Barbosa-Gimenez \& Caetano-Chang (1998) classificam esses arenitos como subarcóseos e, subordinadamente, como sublitarenitos, quartzarenitos e arcóseos.

O presente trabalho teve por alvo o estudo diagenético de arenitos da Formação Tatuí, consubstanciado por análises petrográficas detalhadas de amostras de arenitos de subsuperfície e superfície, coletadas em poços e afloramentos da unidade no estado de São Paulo (Fig. 1). Essas análises petrológicas foram dirigidas exclusivamente à diagnose dos processos diagenéticos (químicomineralógicos e físicos) que atuaram nesses arenitos.

Estudos sobre a petrografia e, particularmente, sobre a diagênese de rochas da Formação Tatuí são escassos, de forma que o presente estudo vem preencher essa lacuna na literatura sobre a unidade.

MÉTODOS Neste estudo, foram utilizadas amostras de arenitos coletadas a partir de testemunhos contí- nuos e de amostras de calhas de poços perfurados pela PETROBRAS (2-AR-1-SP, 2-LA-1-SP, 2-TB-1-SP, 2-AA-1-SP, 1-PA-1-SP, 2-PN-1-SP, 1-SA-1-SP, 1-AB1-SP, no estado de São Paulo, e 2-RI-1-PR, no estado do Paraná, próximo a São Paulo) e pela CPRM (PL-02, PL-10 e PL-07), além de amostras de superfície coletadas em algumas das melhores exposições de arenitos da Formação Tatuí no estado de São Paulo (km 150 e km 152,5 da Rodovia do Açúcar - SP 308; km 15 da estrada vicinal que liga Araras a Leme, Distrito de Ibicatú; e Serra dos Pais, em Barão de Antonina - Fig. 1).

O trabalho centrou-se na análise, ao microscópio óptico, de 60 lâminas delgadas, sendo 44 de subsuperfície e 16 de superfície. Para confecção dessas lâminas foram utilizadas amostras impregnadas a vácuo, com resina epoxy azul, segundo técnica modificada de Cesero et al. (1989) que permite a melhor identificação dos espaços porosos. Grande parte das lâminas passou por processo de tingimento com solução de $0,15 \%$ de $\mathrm{HCl}, 1 \%$ de ferricianeto de potássio e $0,1 \%$ de alizarina (método de Evamy 1969), para identificação dos diferentes tipos e composição de cimentos carbonáticos.

A técnica de catodoluminescência foi utilizada em 12 lâminas delgadas, com vistas à melhor caracterização de fases autigênicas de quartzo e feldspa-

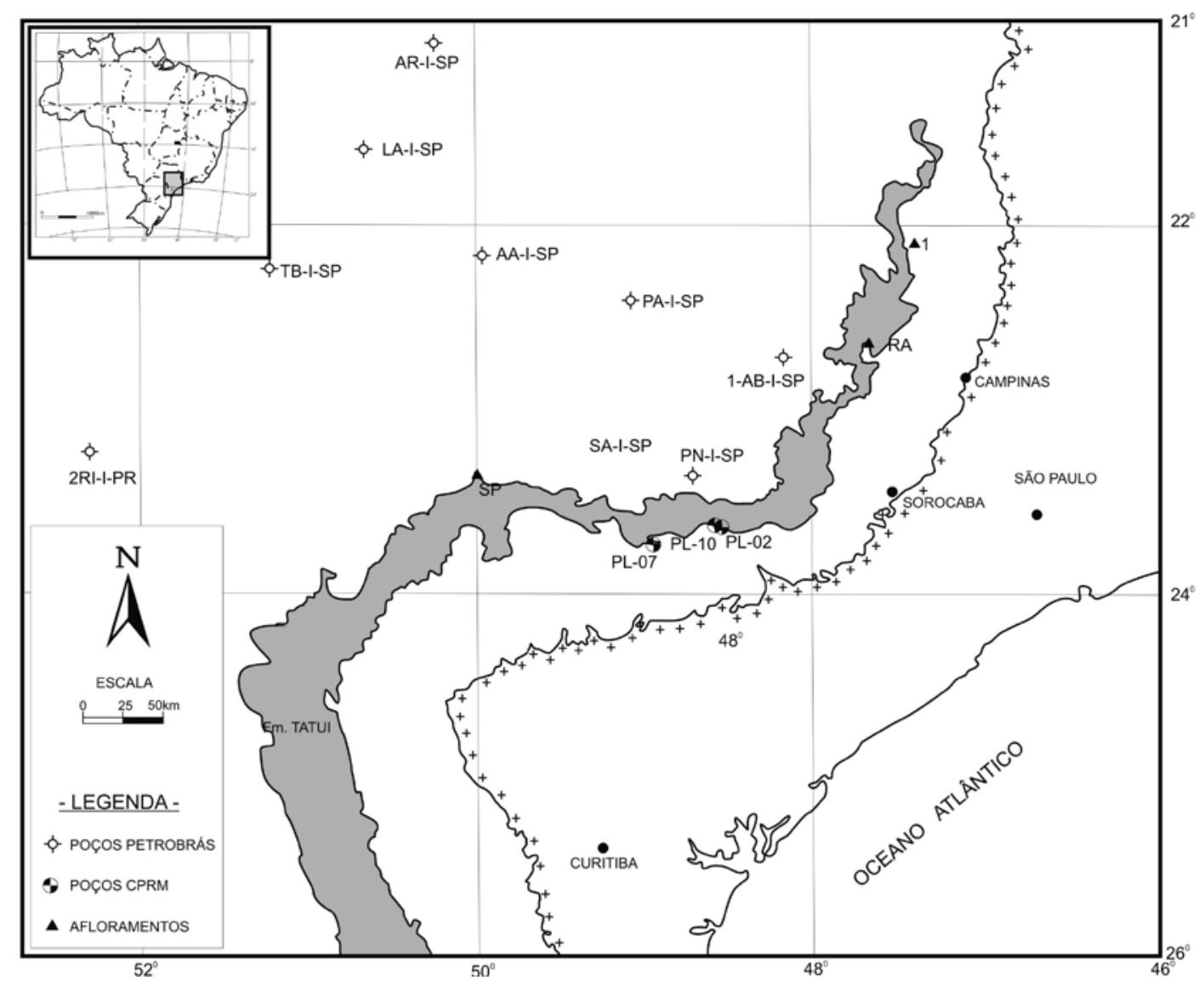

Figura 1 - Mapa de localização de afloramentos e poços amostrados, perfurados pela PETROBRAS e CPRM. 
to, das diferentes gerações de cimento, e de eventuais zoneamentos composicionais. A catodoluminescência baseia-se na captação da luminescência produzida pelo mineral quando submetido a um feixe de elétrons energizados. Para este estudo, foi utilizado o método descrito por Matter \& Ramseyer (1985 in Zuffa 1985) e Gomes \& Vortish (1991).

\section{RESULTADOS}

Composição mineralógica Segundo Barbosa-Gimenez (1996) e Barbosa-Gimenez \& Caetano-Chang (1998), os arenitos da Formação Tatuí são compostos basicamente por quartzo e feldspatos e, subordinadamente, por fragmentos de rocha e minerais acessórios.

O quartzo é o mineral dominante nos arenitos da unidade, ocorrendo tanto na forma de quartzo monocristalino (predominante) quanto policristalino, estes mais frequentes em arenitos com granulometria mais grossa. Os feldspatos representam cerca de $16 \%$ dos minerais do arcabouço desses arenitos, sendo constituídos predominantemente por ortoclásio, seguido por plagioclásio alcalino, microclínio e pertita.

Os fragmentos líticos compõem apenas cerca de $1 \%$ do arcabouço dos arenitos da Formação Tatuí, sendo mais frequentes nas frações areias média e grossa; são representados por líticos metamórficos (gnaisse, quartzito, xisto e ardósia), ígneos (granito e vulcânicas básicas) e sedimentares (sílex, arenito, calcário, siltito e argilito).

Os principais minerais acessórios encontrados nesses arenitos são micas (moscovita, clorita e biotita), zircão, turmalina, rutilo, epidoto, hornblenda e apatita. As micas, que geralmente não ultrapassam $2 \%$ da composição total, podem chegar a $10 \%$ em arenitos muito finos.

A matriz dos arenitos da Formação Tatuí, em geral inferior a $5 \%$, é constituída por caulinita, ilita, esmectita e clorita, ocorrendo, localmente, matriz tufácea de composição ácida (sílica opalina).

Evolução diagenética Para caracterização da evolução diagenética desses arenitos, foram analisados os processos de recristalização, dissolução, substituição e cimentação dos grãos do arcabouço, que são, de modo geral, resultantes da compactação e da interação entre os grãos e os fluidos intersticiais, nos diferentes regimes diagenéticos - eodiagenético, mesodiagenético e telodiagenético (Choquette \& Pray 1970, Schmidt \& McDonald 1979) - sob atuação dos diferentes regimes hidrológicos - meteórico, termobárico e compactacional (Galloway 1984).

Para Morad et al. (2000), a separação entre os regimes eo e mesodiagenético ocorre em condições encontradas a aproximadamente $2000 \mathrm{~m}$ de profundidade de soterramento e temperatura de cerca de $70^{\circ} \mathrm{C}$, situação em que se avolumam as transformações químicas nos minerais.

EODIAGÊENESE Durante o regime eodiagenético, a circulação de água meteórica nos sedimentos arenosos da Formação Tatuí teve provavelmente curta duração. Segundo Bjorlykke (1984), mesmo os sedimentos depositados em ambiente marinho raso podem ser percolados por águas de origem meteórica, em profundida- des de várias dezenas a algumas centenas de metros. A circulação de água meteórica na unidade foi provavelmente abortada de forma gradual, à medida que a linha de costa regredia devido à transgressão marinha.

Como processos característicos dessa fase foram observadas substituição de bioclastos, dissolução de minerais instáveis e precipitação de calcita microcristalina, pirita e óxidos de ferro. A sequência dos processos eodiagenéticos identificados, apresentada a seguir, inclui substituição e dissolução de grãos do arcabouço e precipitação de cimentos.

Substituição de bioclastos Nos intervalos totalmente cimentados por calcita microcristalina, nota-se grande quantidade de grãos do arcabouço substituída por este cimento. É provável que grande parte desses grãos seja de origem aloquímica, pois, em alguns intervalos, observase a presença de carapaças calcárias, provavelmente de bivalves, embutida em cimento carbonático (Fig. 2A).

Dissolução de minerais instáveis Nos arenitos estudados, os minerais pesados são pouco abundantes, sendo representados principalmente por minerais ultraestáveis (zircão, turmalina e rutilo). Segundo BarbosaGimenez (1996), devido ao caráter de suas rochas-fonte seria de se esperar maior quantidade e variedade desses minerais acessórios. Assim, a baixa frequência desses minerais pode estar relacionada à dissolução eodiagenética, que atinge os minerais segundo a série de Goldich (Goldich 1938), que corresponde ao inverso da sequência de Bowen.

A dissolução de minerais instáveis pode ter contribuído para a formação de porosidade secundária.

Precipitação de cimento ferruginoso A dissolução de minerais pesados deve ter contribuído para a precipitação de óxidos e hidróxidos de ferro, assim como para o aumento da concentração de íons como $\mathrm{Fe}^{2+}$ e $\mathrm{Mg}^{2+} \mathrm{em}$ solução. Walker (1976 apud Morad 1991) ponderou que a maior parte dos cimentos de hematita em arenitos seria formada pela alteração diagenética de minerais detríticos portadores de ferro (biotita, anfibólio, piroxênio, magnetita e óxidos de Fe e Ti).

Nos arenitos da Formação Tatuí é comum a presença de minerais formados por óxidos de ferro (provavelmente magnetita) e titânio (ilmenita ou titano-magnetita); é também comum a alteração de biotita para clorita (Fig. 2B), liberando dessa forma oelemento ferro. O ferro liberado das reações de alteração da biotita pode ocorrer como íons férrico ou ferroso, dependendo das condições de Eh e $\mathrm{pH}$ vigentes: o íon ferroso $\left(\mathrm{Fe}^{2+}\right)$ continua em solução ou é incorporado a fases autigênicas como a pirita e a esmectita, enquanto o íon férrico $\left(\mathrm{Fe}^{3+}\right)$, pouco solúvel, precipita como óxido ou hidróxido de ferro (Walker 1976 apud Morad 1991).

Precipitação de calcita microcristalina Segundo Folk (1974), a mineralogia e a morfologia dos diferentes minerais carbonáticos são controladas pela atividade do íon $\mathrm{Mg}^{2+}$ e de outros íons (principalmente $\mathrm{Na}^{+}$) existen- 

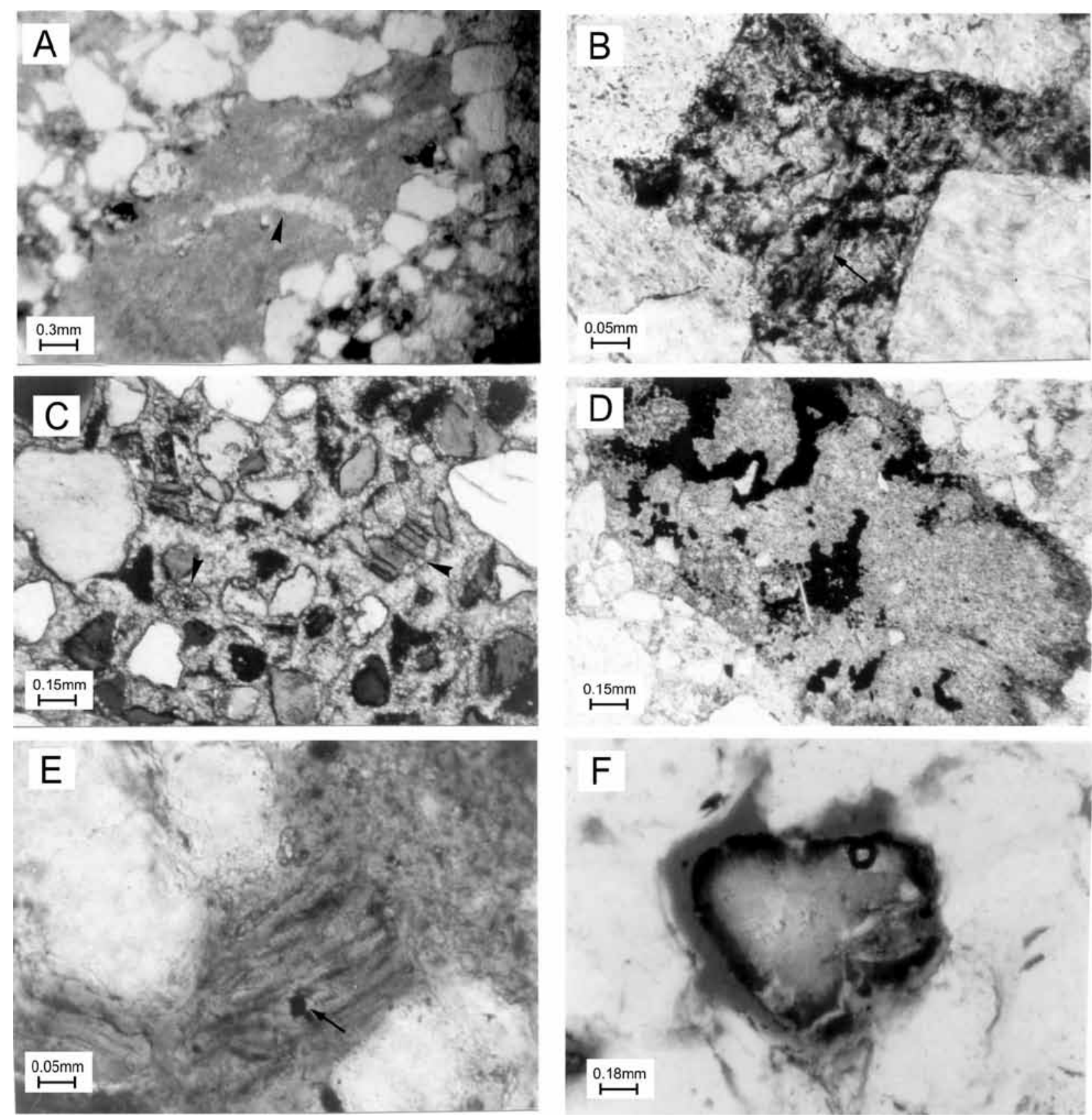

Figura 2 - A. Bioclasto embutido em cimento carbonático (Am. 2-LA-1-SP, 2325,90m. N//); B. Alteração de biotita para clorita (Am. 1-PA-1-SP, 708m. N//); C. Grãos do arcabouço com substituição, parcial e total, por cimento de calcita microcristalina (Am. 2-LA-1-SP, 2322,95m. NX.); D. Agregado de pirita framboidal distribuida ao redor e internamente ao cimento de calcita (Am. 23-PL-02, 87,00m. N//); $\boldsymbol{E}$. Pirita associada à biotita, que se apresenta parcialmente cloritizada (Am. 2-PN-1-SP, 228,00m. N/I); $\boldsymbol{F}$. Contração em fragmento de argilito e porosidade secundária (Am. 2-PN-1-SP, 228,00m. N//).

tes nos fluidos cimentantes e, também, pela taxa de crescimento dos cristais. A presença do íon $\mathrm{Mg}^{2+}$ inibe a formação de macrocristais de calcita, pois impede o livre crescimento dos cristais e o desenvolvimento de faces laterais, criando uma textura microcristalina comum em ambientes marinhos. Moore (1989) afirma que a textura microcristalina em cimentos carbonáticos é produto da rápida precipitação próximo à superfície, associada a processos orgânicos e a reações químicas que causam rápida supersaturação e múltipla nucleação.
Esta cimentação parece ter sido precoce, uma vez que os intervalos cimentados apresentam empacotamento frouxo, com grande quantidade de grãos imersos no cimento e sem evidências de compactação mecânica. Essa característica pode estar relacionada também à substituição de Grãos do arcabouço por estafase cimentante (Fig. 2C).

Segundo Morad (1991), a maior fonte de bicarbonatos para a precipitação de cimento carbonático em sedimentos marinhos são os carbonatos detríticos (prin- 
cipalmente fragmentos esqueletais compostos de aragonita e de calcita com alto ou baixo teor de magnésio, e fragmentos de rocha carbonática) e a água marinha. Argilominerais, plagioclásios e minerais pesados são fontes de $\mathrm{Ca}^{2+}{\mathrm{e} \mathrm{Mg}^{2+} \text {. }}$.

Precipitação de pirita Parte do cimento de pirita, encontrado nos arenitos estudados, pode estar associada à redução de sulfato. Segundo Gautier (1985), o $\mathrm{H}_{2} \mathrm{~S}$ produzido nessa reação combina-se rapidamente com $\mathrm{Fe}^{2+}$ em solução, resultando na precipitação de sulfetos metaestáveis, os quais se transformam em pirita com hábito framboidal (Fig. 2D). Esta ocorre como feições localizadas, geralmente associadas à calcita não-ferrosa.

Pode-se notar a ocorrência de pirita euédrica associada à biotita alterada (Fig. 2E). Durante o processo de alteração, há liberação do ferro existente em sua composição que, associado ao sulfeto resultante de maturação da matéria orgânica (redução de sulfato), precipita a pirita. Segundo Morad (1991), a cloritização da biotita é uma fonte de ferro importante para a precipitação da pirita.

Crescimento secundário de feldspato potássico O feldspato potássico autigênico forma-se, comumente, durante a eodiagênese, e pode tornar-se instável e parcialmente dissolvido ou pode ser substituído por outros minerais diagenéticos durante a mesodiagênese, devido a mudanças na química dos fluidos dos poros (Morad 1991).

Bioturbação Além dos processos acima descritos, foram também observadas feições de bioturbação nos arenitos. A atividade de organismos perfuradores nos sedimentos modifica o arranjo de seu espaço poroso, pela introdução de grãos mais finos (silte a areia muito fina) em meio aos grãos mais grossos (areia média a grossa), homogeneizando-os e formando localmente feições arredondadas.

Porosidade de contração Os argilominerais sofrem desidratação, resultando em perda de volume. Com isto, fragmentos argilosos, principalmente intraclastos de argilitos e folhelhos, rompem-se e descolam-se dos grãos do arcabouço e do cimento, formando porosidade secundária (Fig. 2F - porosidade de contração ou shrinkage).

MESODIAGÊNESE No ambiente mesodiagenético, cessa a influência dos processos superficiais representados pela infiltração de águas meteóricas. Os arenitos da Formação Tatuí, durante a mesodiagênese, foram percolados por fluxos compactacionais e termobáricos e submetidos a diferentes fases diagenéticas como compactação, precipitação e dissolução de vários tipos de cimento, cuja sequência é apresentada a seguir.

Compactação Embora a deformação de grãos incompetentes possa começar no regime eodiagenético, é principalmente no inicio da mesodiagênese, definido como estágio imaturo por Schmidt \& McDonald (1979), que a pressão litostática eleva-se o suficiente para desencadear este processo.

Nos arenitos da Formação Tatuí, a compactação mecânica é limitada, provavelmente inibida, quando a cimentação por quartzo e carbonato (calcita poiquilotópica e em mosaicos) é intensa. A substituição de grãos do arcabouço por cimento carbonático muitas vezes dificulta a avaliação precisa do grau de compactação anterior à precipitação dos cimentos.

As evidências de compactação são representadas por deformações de micas, grãos de feldspatos (Fig. 3A) e intraclastos argilosos. Algumas amostras mostram intensa compactação, com contatos côncavoconvexos ou mesmo suturados entre grãos, graças a intenso processo de pressão-solução (Fig. 3A).

Crescimento secundário de quartzo A formação de sobrecrescimento de quartzo (Fig. 3B) está relacionada à forte tendência dos íons de sílica em precipitarem-se segundo a estrutura cristalográfica do grão hospedeiro (Blatt et al. 1980); representa o primeiro evento mesodiagenético de importância nos arenitos estudados, sendo anterior à cimentação por calcita mesodiagenética.

A fonte de sílica para a precipitação deste cimento pode estar relacionada à dissolução de grãos de sílex, quartzo e silicatos em geral, a alterações de argilominerais durante o soterramento, à pressão-solução de quartzo do arcabouço, à caulinização ou dissolução de feldspato nos arenitos e à dissolução de grãos de quartzo nos folhelhos.

Crescimento secundário de plagioclásio Este tipo de cimento (Fig. 3C) foi reconhecido somente em algumas amostras, representando uma fase cimentante posterior à do quartzo (Fig. 3D) e provavelmente anterior à da calcita, uma vez que, nas amostras em que foi observado, o cimento carbonático apresentava-se dissolvido e os sobrecrescimentos de plagioclásio corroídos.

A fonte mais provável de alumínio e potássio para a formação desses sobrecrescimentos são os feldspatos detríticos e grãos líticos contendo feldspato que sofreram dissolução intra-estratal, enquanto a fonte de sílica é a mesma dos crescimentos secundários de quartzo.

Cimentação por calcita poiquilotópica e em mosai$\cos$ A calcita em mosaico apresenta-se fortemente zonada com relação ao teor de ferro. Esse padrão de zoneamento mostra claramente que a calcita ferrosa precipitou-se posteriormente à calcita pura, devido ao enriquecimento em ferro.

A calcita poiquilotópica ocorre como grandes cristais envolvendo os grãos do arcabouço e fases autigênicas mais precoces (Fig. 3E). A cimentação e a substituição dos grãos do arcabouço por essa fase são intensas, resultando em empacotamento com aspecto frouxo (Fig. 3E).

Em ambiente mesodiagenético, a precipitação de cimento calcítico em arenitos ocorre com maior facilidade, uma vez que a solubilidade da calcita diminui com o aumento da temperatura. As possíveis fontes de cálcio para estes cimentos são: fo- 

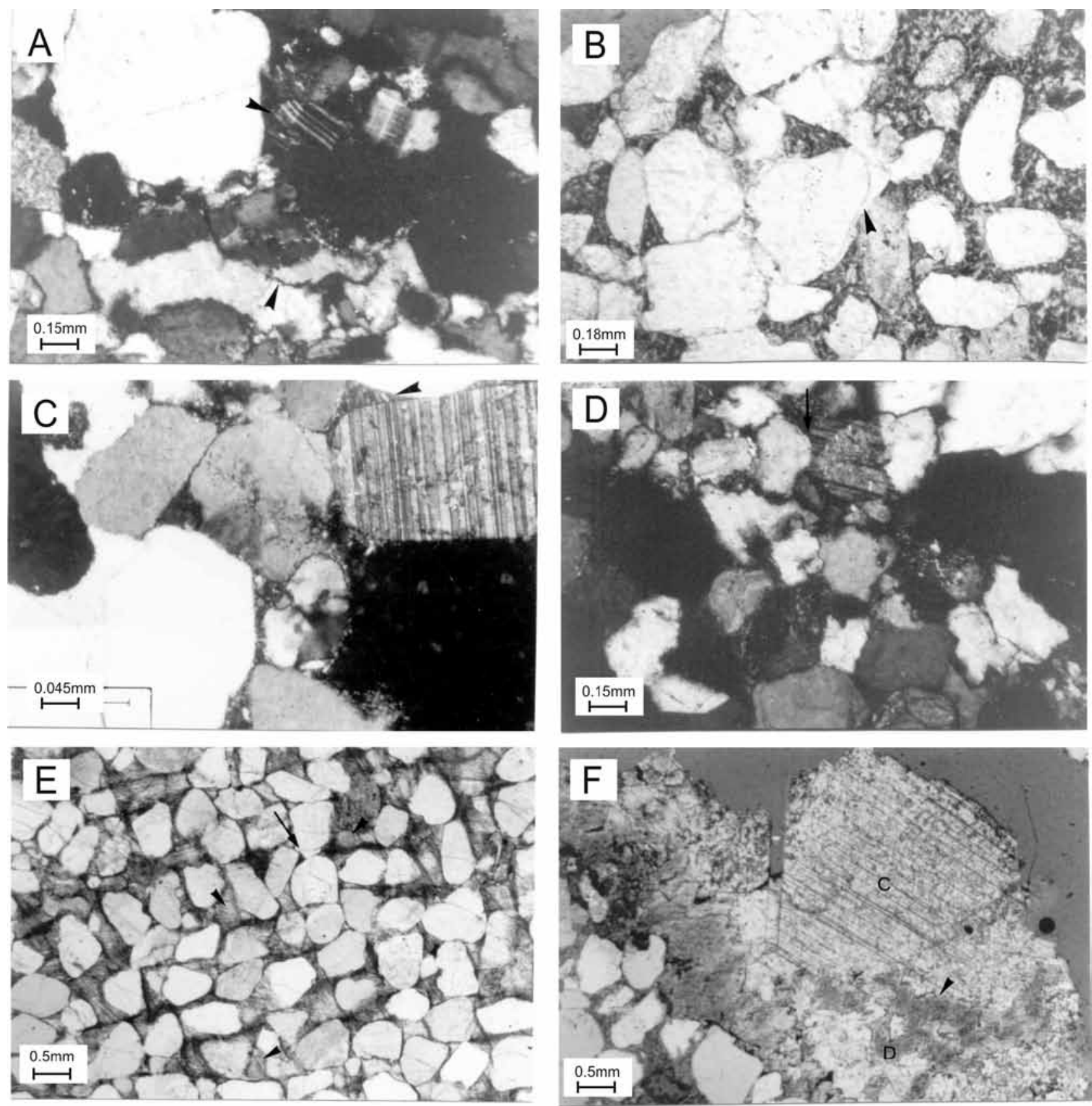

Figura 3 - A. Grão de feldspato deformado e grãos de quartzo com pressão-solução (Am. LA-1-SP, $2352,00 \mathrm{~m}$. NX); B. Crescimento secundário sintaxial em torno de grãos de quartzo (overgrowth) (Am. LA1-SP, 2352,00m. N//); $\boldsymbol{C}$. Grão de plagioclásio com crescimento secundário. Notar que o sobrecrescimento apresenta-se também maclado (Am. AA-1-SP, 1920,00m. NX); D. Cimento de feldspato posterior ao cimento de quartzo. Notar que o sobrecrescimento de plagioclásio não apresenta alteração (Am. AA-1-SP, 1920,00m. $N X) ; \boldsymbol{E}$. Cimento de calcita poiquilotópica (levemente ferrosa) envolvendo grãos do arcabouço e fases autigênicas mais precoces (cimento ferruginoso e sobrecrescimento de quartzo). Notar presença de grãos substituidos por calcita (Am. 1-PA-1-SP, 707,60m. N//); F. Cimento de dolomita precipitado posteriormente ao cimento de calcita poiquilotópica (Am. LA-1-SP, 2298,00m. N//).

lhelhos adjacentes, dissolução de fósseis, dissolução de cimento microcristalino (remobilização interna) e dissolução por pressão em carbonatos adjacentes.

Cimentação por dolomita Os cimentos dolomíticos (dolomita pura, dolomita ferrosa e anquerita) formaram-se provavelmente por substituição de minerais car- bonáticos preexistentes. A dolomita pura ocorre posteriormente ao cimento de calcita poiquilotópica e em mosaico (Fig. 3F). Em algumas amostras, a dolomita ferrosa e a anquerita aparecem associadas à calcita ferrosa e à dolomita pura, indicando que se formaram tanto pela alteração da calcita como pelo enriquecimento de ferro em dolomita preexistente. 
Segundo Boles (1978), a anquerita se forma a partir da calcita ou da dolomita em temperaturas entre $80^{\circ} \mathrm{C}$ e $120^{\circ} \mathrm{C}$, sendo importante a presença de argilominerais para sua formação. A transformação de esmectita em ilita, com o aumento do soterramento e da temperatura, pode ser o principal controlador dessas reações (Perry \& Hower 1972).

Durante o soterramento, a temperatura mais elevada possibilita a formação de dolomita, pois reduz os fatores cinéticos desfavoráveis à precipitação desses carbonatos. Christ \& Hostetler (1970) sugerem que a precipitação de dolomita, a baixa temperatura, é dificultada pelo alto poder de hidratação do íon magnésio. Segundo Baker \& Kastner (1981), a presença de sulfato nas soluções intra-estratais inibe a precipitação de dolomita. Em subsuperfície, no entanto, o teor de sulfatos é normalmente reduzido, pois estes são consumidos em processos anteriores, na zona de redução do sulfato.

Dissolução de calcita e feldspato A presença de poros agigantados e de grãos e cimentos com características de corrosão indicam que fluidos agressivos (ácidos) causaram a dissolução parcial ou total dos minerais, formando porosidade secundária. A hipótese mais conhecida para a geração de fluidos ácidos, em superfície, é a produção de $\mathrm{CO} 2$ a partir da matéria orgânica depositada em folhelhos (Schmidt \& McDonald 1979). $\mathrm{O} \mathrm{CO}_{2}$ pode ser produzido pela descarboxilação térmica da matéria orgânica durante a maturação dos folhelhos que, na presença de água, produz ácido carbônico. Dessa forma, os fluidos ácidos migram para os arenitos adjacentes, dissolvendo os carbonatos e feldspatos.

Os processos de dissolução são reconhecidos como relativamente tardios em uma sequência de eventos diagenéticos. Segundo Schmidt \& McDonald (1979), os fluidos responsáveis pela dissolução são gerados em profundidades moderadas de soterramento (entre $1000 \mathrm{~m}$ e $3000 \mathrm{~m}$ ).

A dissolução direta de minerais silicáticos, tais como quartzo e feldspato, cria pouca ou nenhuma porosidade, pois esta ocorre ao longo dos contatos. Esses minerais são geralmente substituídos por outros não-silicáticos (principalmente carbonatos) e dissolvidos posteriormente, criando então porosidade secundária (Fig. 4A). Nos feldspatos, esta substituição se dá ao longo dos planos de clivagem (Fig. 4B), formando porosidade do tipo honeycombed.

Caulinita mesodiagenética A precipitação de caulinita, preenchendo porosidade secundária formada pela dissolução de cimento de calcita e de grãos de feldspatos, foi reconhecida em diversas amostras parcialmente cimentadas por carbonatos e/ou porosas.

Curtis (1983) argumenta que a precipitação de caulinita ocorre simultaneamente à dissolução de calcita. A solubilidade da caulinita é função da atividade do íon alumínio na solução, da solubilidade da sílica e do $\mathrm{pH}$ do fluido, sendo que o aumento do $\mathrm{pH}$ causado pela dissolução de calcita favorece a precipitação da caulinita.
A caulinita desta fase apresenta-se como agregados bem formados, preenchendo poros de origem secundária (Fig. 4C) ou substituindo feldspatos (Fig. 4D).

Precipitação de calcita tardia A dissolução de cimentos carbonáticos de fases anteriores, por fluidos ácidos, pode causar supersaturação local, possibilitando múltipla nucleação com precipitação de calcita (Fig. 4E). Esta calcita constitui, portanto, reciclagem dos carbonatos de fases anteriores.

Albitização de feldspatos Os grãos de feldspato nos arenitos da Formação Tatuí apresentam-se em grande parte albitizados. Evidências mostrando substituição de plagioclásio e feldspato potássico por albita foram observadas por meio de catodoluminescência. A albitização diagenética de feldspatos é largamente reconhecida na literatura especifica (Boles 1982, Gold 1987, Saigal et al. 1988, Morad et al. 1990).

A albitização pode ser dar como intercrescimento (intergrowth) e como substituição total em feldspato potássico e plagioclásio (Fig. 4F). Nos arenitos aqui estudados, este processo é mais intenso nos de granulometria mais grossa, cuja textura teria favorecido a percolação de fluidos e a consequente alteração dos feldspatos.

Segundo Morad (1988), a albitização se processa pelo mecanismo de dissolução-precipitação. Em profundidades rasas, a dissolução de feldspato é mais rápida que a precipitação de albita. A albitização tende a estar presente e a aparecer na forma de manchas em profundidade de até $3 \mathrm{~km}$, enquanto em profundidades maiores é completa. $\mathrm{O}$ fato de a albitização ser mais pronunciada em maiores profundidades sugere que o processo é favorecido por temperaturas mais altas.

A albitização requer suprimento de sódio, bem como mecanismo que consuma potássio. Segundo Boles \& Franks (1979), as prováveis fontes de sódio estão na conversão diagenética de esmectita para ilita nos folhelhos intercalados e na substituição de grãos detríticos de feldspatos. A alteração de esmectita para ilita consome $\mathrm{K}^{+}$e libera $\mathrm{Na}^{+}$, segundo a reação (1), possibilitando troca de íons entre arenitos e folhelhos.

$$
\mathrm{KAlSi}_{3} \mathrm{O}_{8}+\mathrm{Na}^{+}==>\mathrm{NaAlSi}_{3} \mathrm{O}_{8}+\mathrm{K}^{+}
$$

Saigal et al. (1988) argumentam que a albitização pode se iniciar em temperaturas a partir de 65 ${ }^{\circ} \mathrm{C}$, caso haja suprimento suficiente de sódio para esta transformação. Boles (1982) descreve feições de albitização em temperaturas mais elevadas, acima de $110^{\circ} \mathrm{C}$.

Precipitação de zeólita Este mineral ocorre bem desenvolvido e associado à calcita poiquilotópica e a grãos de vidro vulcânico. Segundo Morad (1991), alterações de plagioclásio cálcico e de vidros vulcânicos constituem as fontes de íons $\mathrm{Na}^{+}, \mathrm{Si}^{4+}$ e $\mathrm{Al}^{3+}$, necessários para formação do cimento de zeólita.

A formação da zeólita, a partir de vidro vulcânico, libera sílica. Segundo Deffeyes (1959), este pro- 

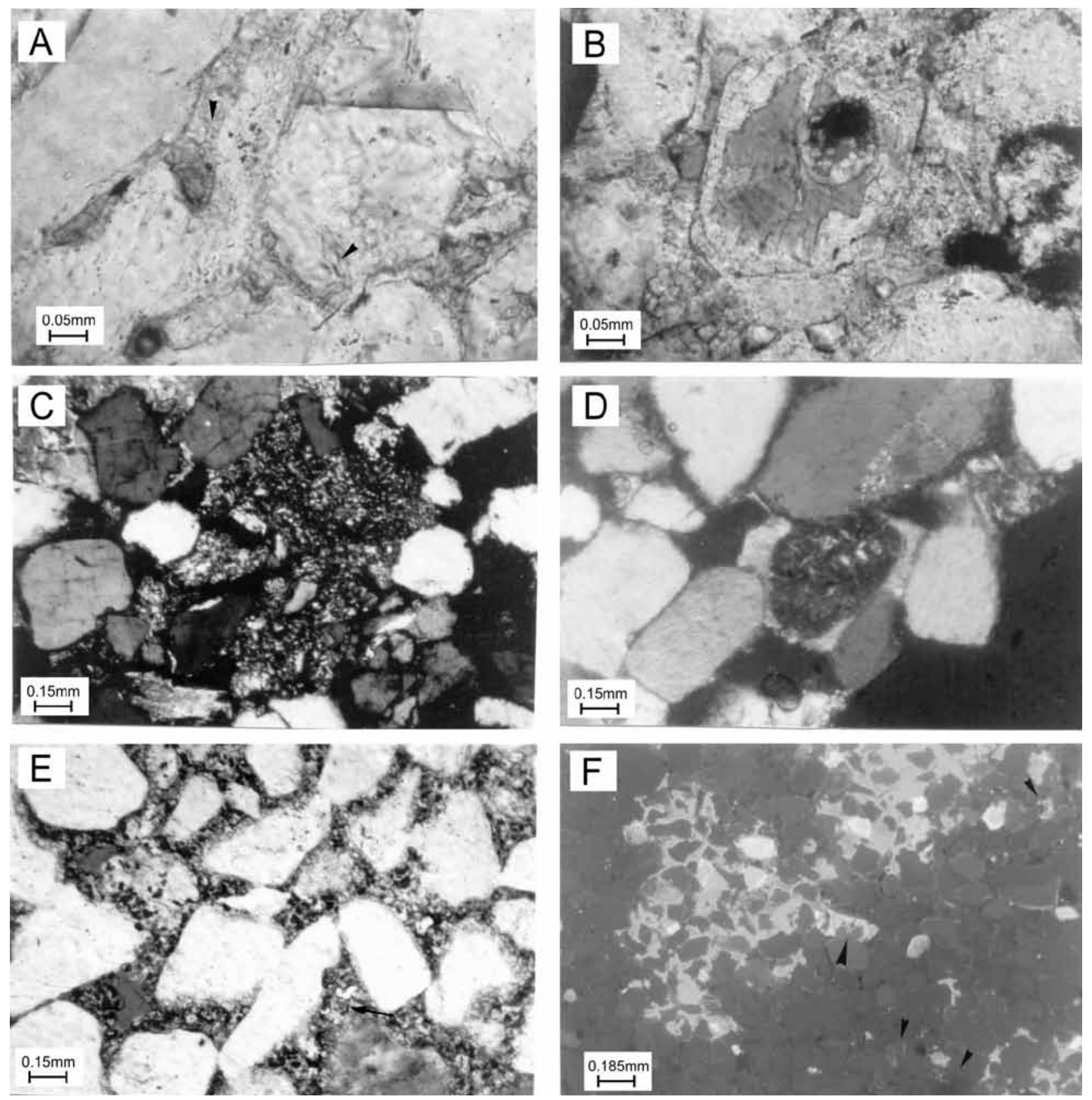

Figura 4 - A. Feições de dissolução em grãos do arcabouço, criando porosidade secundária (Am. PN1-SP, 228,00m. N//); B. Grão de feldspato com dissolução interna, ao longo dos planos de clivagem. Notar crescimento secundário do feldspato (Am. AR-1-SP, 1938,00m. N//); C. Precipitação de caulinita autigênica após dissolução do cimento carbonático (Am, PN-1-SP, 228,00m. NX); D. Grão de feldspato com substituição por caulinita (Am. LA-1-SP, 2352,00m. NX); E. Cimento de calcita tardia precipitado em porosidade intergranular secundária, originada pela dissolução de cimento carbonático de fases anteriores; é formado por pequenos cristais subédricos a euédricos, apresentando zoneamento quanto ao teor de ferro (Am. LA-1-SP, 2352,00m. N//); F. Fotomicrografia de catodoluminescência mostrando grãos de feldspato potássico e plagioclásio (setas) em processo de albitização (Am. RI-1-PR, 2688,50m. CL).

cesso ocorre devido ao mecanismo de reação entre o vidro vulcânico e águas salinas e alcalinas nos poros dos sedimentos.

Cimentação por anidrita $\mathrm{O}$ cimento de anidrita foi observado em várias amostras de arenitos da unidade; ocorre como cristais poiquilotópicos (Fig. 5A) de uma fase cimentante posterior à carbonática e associada à ocorrência de feldspatos albitizados. A precipitação da anidrita aproveitou-se provavelmente da liberação de cálcio durante o processo de albitização.

Cimentação por anatásio Cristais de anatásio autigênico ocorrem em pequenas quantidades nos arenitos 

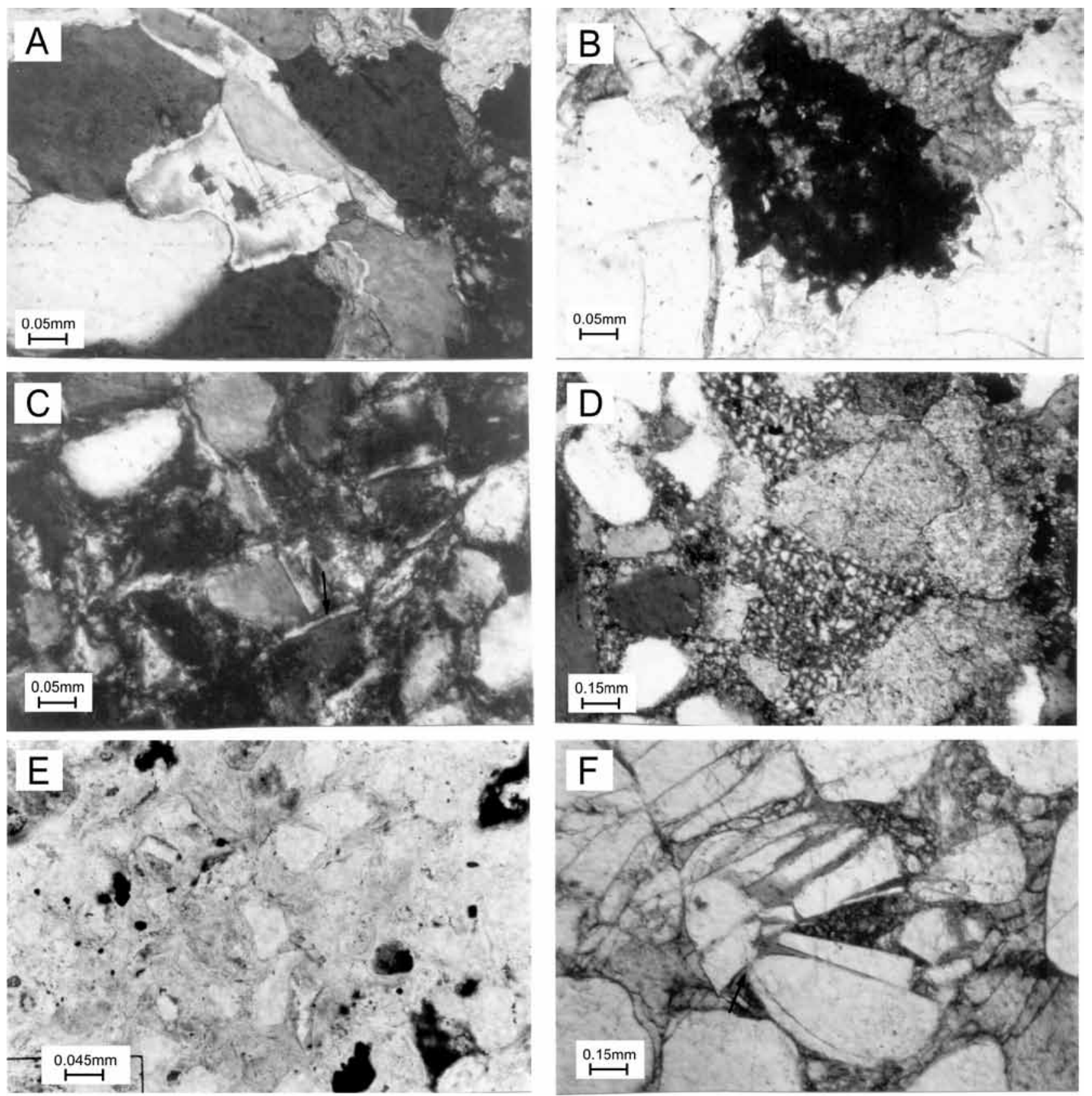

Figura 5 - A. Cimento de anidrita posterior à cimentação carbonática (Am. 2-RI-1-PR, 2688,50m. NX); B. Cristais de anatásio autigênico formados posteriormente à cimentação de calcita em mosaico (Am. 47-PL-10, 170,20m. N//); C. Coatings de calcedônia contornando os grãos do arcabouço (Am. AR-1-SP, 1890,00m. NX); D. Cimento de calcedônia em forma de agregados esferulíticos (Am. TB-1-SP, 2775,00m. $N X) ; \quad$ E. Arenito cimentado por sílica (Am. AR-1-SP, 1896,00m. N//); F. Arenito com fraturas posteriores ao sobrecrescimento de quartzo e exibindo porosidade secundária (Am. PA-1-SP, 707,60m. N//).

estudados (Fig. 5B). Segundo Morad (1991) e De Ros (1987), os íons de titânio, necessários à formação desses minerais, originam-se in situ a partir da alteração de grãos detríticos de óxidos de ferro-titânio e minerais ricos em titânio, como titanita e biotita.

Cimentação por sílica Nos arenitos da Formação Tatuí em que os polimorfos de sílica ocorrem associados a vidro vulcânico, zeólita e esmectita, é provável que a opala tenha se formado pelo desprendimento de sílica durante a formação da zeólita. A transformação da opala em calcedônia é indicada pela presença de filmes de calcedônia contornando os grãos do arcabouço, assemelhando-se a argilomineral infiltrado mecanicamente (Fig. 5C). O microquartzo, na forma de sílex, também ocorre associado. Dessa forma, observa-se um trend de transformação desses polimorfos, resultando também na formação de argilomineral (esmectita).

Em amostras que não apresentam polimorfos de sílica associados a vidro vulcânico, sua origem pode 
estar relacionada à substituição de argilominerais por opala, em uma fase inicial (Morad 1991). A calcedônia ocorre, também, como agregados radiados esferulíticos (Fig. 5D). Segundo Morad (1991), altas concentrações de álcalis nos fluidos dos poros levam ao desenvolvimento de quartzo microcristalino. A associação do microquartzo com argilominerais da matriz está relacionada à maior quantidade de sílica nos níveis argilosos.

Cimentos de opala, calcedônia e sílex precipitaram-se em microporos dos arenitos da unidade e substituíram a matriz, resultando em uma mistura difusa (Fig. 5E), isotrópica, com aspecto turvo, de cores marrom e esverdeada.

TELODIAGÊNESE A retomada da infiltração de água de origem meteórica, decorrente do soerguimento da Formação Tatuí, determinou a implantação do regime telodiagenético, promovendo condições oxidantes que favoreceram a precipitação de óxidos de ferro, como observado nas amostras de superfície e do poço PL-02, próximas à superfície.

As amostras de superfície apresentam-se com feições de dissolução em feldspato e não contêm cimento carbonático, provavelmente lixiviado neste novo ambiente, criando porosidades secundárias intragranulares e intergranulares.

É comum a ocorrência de caulinita nas amostras de superfície, assim como é pouco frequente a presença de feldspato nas mesmas. Dessa forma, pode-se dizer que os feldspatos foram, em sua maior parte, caulinizados.

Considerações adicionais Algumas amostras dos arenitos estudados apresentam-se fraturadas, provavelmente devido a esforços tectônicos. No entanto, em amostra do poço 1-PA-1-SP $(707,60 \mathrm{~m})$, foram observadas fraturas com características peculiares, ocorridas em fase posterior à cimentação por sobrecrescimento de quartzo e de carbonato, como é o caso da figura $5 \mathrm{~F}$, em que os grãos de quartzo estão fatiados em lascas, levemente deslocadas ou separadas entre si. Esse tipo de ocorrência em amostra de arenito da Formação Tatuí, proveniente de poço perfurado na estrutura de Piratininga, pode corroborar a hipótese da origem criptoexplosiva dessa estrutura (Astroblema de Piratininga), aventada por Hachiro et al. (1994).

De um modo geral, as fraturas contribuem para a formação de porosidades secundárias.

CONCLUSÕES Os arenitos da Formação Tatuí tiveram sua história diagenética desenvolvida em regimes eodiagenético e mesodiagenético e, quando à superfície ou próximos dela, também em regime telodiagenético.

$O$ detalhamento das relações petrográficas entre eventos de cimentação, dissolução e substituição, dentre outros observados em arenitos da unidade, permitiu estabelecer a sequência de eventos diagenéticos representada na figura 6 .

O regime eodiagenético foi marcado por substituição de bioclastos (carapaças calcárias de bivalves), dissolução de minerais instáveis e precipitação de cimentos de calcita microcristalina, pirita, feldspato potássico e óxidos de ferro. A eodiagênese foi influenciada pela circulação de águas meteóricas nos sedimentos da Formação Tatuí, fenômeno esse gradualmente abortado, à medida que a linha de costa regredia pela transgressão marinha que marcou a deposição da unidade.

No ambiente mesodiagenético, esses arenitos passaram a ser percolados por fluxos compactacionais e termobáricos, resultando em diferentes fases diagenéticas. Essas fases são representadas por crescimentos secundários de quartzo e plagioclásio, cimentação por calcita poiquilotópica e em mosaicos, cimentação por dolomita (pura, ferrosa e anquerita), dissolução de calcita e feldspato, precipitação de caulinita e calcita tar-

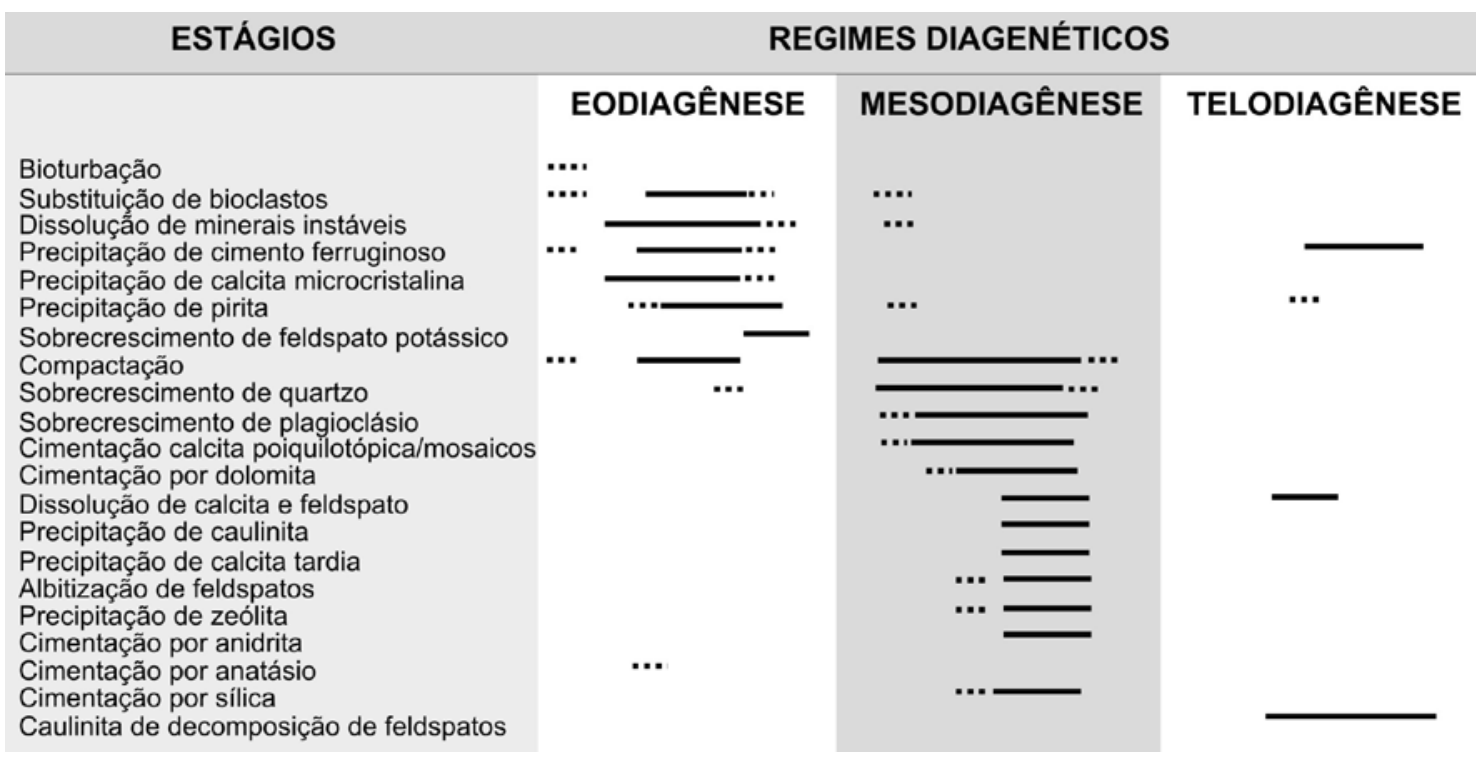

Figura 6 - Sequência de eventos diagenéticos na Formação Tatuí. 
dia, albitização de feldspatos, precipitação de zeólita, cimentação por anidrita, anatásio e sílica.

Durante a telodiagênese deu-se a retomada da infiltração de água de origem meteórica. Os arenitos expostos a esse ambiente apresentam quantidades razoáveis de cimentos ferruginosos e de caulinita, feições de dissolução em feldspato, assim como ausência de cimento carbonático.

A porosidade nesses arenitos é, em grande parte, de origem secundária, sendo representada pelos tipos intergranular, intragranular, móldica, de contração e por fraturas. A intensa cimentação carbonática foi a responsável principal pela destruição da porosidade primária, de forma que a porosidade é expressiva somente em arenitos onde este cimento foi dissolvido.
De um modo geral, a composição e a textura originais dos arenitos da Formação Tatuí foram modificadas por um conjunto de processos diagenéticos que incluem dissolução dos minerais instáveis, substituição de grãos do arcabouço, precipitação de cimento carbonático e de argilominerais, e albitização de feldspatos.

Agradecimentos Nara L. Barbosa-Gimenez agradece ao $\mathrm{CNPq}$ pelo suporte financeiro que permitiu o desenvolvimento dessa pesquisa. As autoras agradecem à PETROBRAS e à CPRM pela cessão de amostras para a análise petrográfica; ao Departamento de Geologia da UFOP, pelo uso do Laboratório de Catodoluminescência; e, em especial,à colaboração do Prof. Dr. Newton Souza Gomes, nas análises de catodoluminescência.

\section{Referências}

Baker P.A. \& Kastner M. 1981. Constraints on the formation of sedimentary rocks. Science, 213: 214-216.

Barbosa-Gimenez N.L. 1996. Estudo Petrológico dos Arenitos da Formação Tatuí no Estado de São Paulo. Dissertação de Mestrado, Instituto de Geociências e Ciências Exatas, UNESP, Rio Claro, 174 p.

Barbosa-Gimenez N.L., Caetano-Chang M.R., Wu, F.T. 1998. Estudo petrográfico dos arenitos da Formação Tatuí no estado de São Paulo. Geociências, 17(1):81-107.

Bjorlykke K. 1984. Formation of secondary porosity: How important is it? In: Mcdonald D.A., Surdam R.C. (eds.) Clastic diagenesis. American Association of Petroleum Geologists, Tulsa. 37:277-286.

Blatt H., Middleton G., Murray R. (eds.) 1980. Origin of Sedimentary Rocks. New Jersey, Prentice-Hall, Englewood Cliffs, $782 \mathrm{p}$.

Boles, J.R. 1978. Active ankerite cementation in the subsurface.Eocene of southwest Texas. Contributions to Mineralogy and Petrology, 68:13-22.

Boles J.R. 1982. Active albitization of plagioclase, Gulf Coast Terciary. The American Journal of Science, 282:165-180.

Boles J.R. \& Franks S.G. 1979. Clay diagenesis in Wilcox Sandstones of southwest Texas: Implications of smectite diagenesis on sandstone cementation. Journal of Sedimentary Petrology, 498(1):55-70.

Cabral Junior M., Campanha V.A., Motta J.F.M., Saad A.R. 1988. Contribuição à estratigrafia e paleogeografia da interface Itararé e Tatuí $(\mathrm{P})$ e considerações sobre sua potencialidade para carvão no Estado de São Paulo. In: SBG, Congresso Brasileiro de Geologia, 35, Belém, Anais, 2:879-886.

Cesero P., Mauro L.M., De Ros L.F. 1989. Técnicas de preparação de lâminas petrográficas e de moldes de poros na Petrobras. Boletim de Geociências da PETROBRAS, Rio de Janeiro, 3(1/2):105-116.

Choquete P. \& Pray L.C. 1970. Geologic nomenclature and classification of porosity in sedimentary carbonates. Bulletin of the American Association Petroleum Geologists, Tulsa, 54:207-250.

Christ C.L. \& Hostetler P.B. 1970. Studies in the system
$\mathrm{MgO}-\mathrm{SiO}_{2}-\mathrm{CO}_{2}-\mathrm{H}_{2} \mathrm{O}$ : The activity product constant of magnesite. The American Journal of Science, 268:439453.

Curtis C.D. 1983. Link between aluminum mobility and destruction of secondary porosity. Bulletin of the American Association Petroleum Geologists, Tulsa, 67:380-393.

De Ros L.F. 1987. Petrologia e características de reservatório da Formação Sergi (Jurássico) no Campo de Sesmaria, Bacia do Recôncavo, Brasil. Rio de Janeiro, Ciências Técnicas de Petróleo, Seção Exploração de Petróleo, PETROBRAS, 19, 107 p.

Deffeyes K.S. 1959. Zeolites in sedimentary rocks. Journal of Sedimentary Petrology, 29(4):602-609.

Evamy B.D. 1969. The precipitation environment and correlation of some calcite cements deduced from artificial staining. Journal of Sedimentary Petrology, 39:787-821.

Folk R.L. 1974. The natural history of crystalline calcium carbonates: effect of magnesium content and salinity. Journal of Sedimentary Geology, 44:40-53.

Fúlfaro V.J., Stevaux J.C., Souza Filho E.E., Barcelos J.H. 1984. A Formação Tatuí (P) no Estado de São Paulo. In: SBG, Congresso Brasileiro de Geologia 33, Rio de Janeiro, Anais, 2:711-724.

Galloway W.E. 1984. Hidrologic regimes of sandstones diagenesis. The American Association of Petroleum Geologists Sp. Pub., Tulsa, 37:3-13.

Gautier D.L. 1985. Interpretation of early diagenesis in ancient marine sediments. In: Gautier D.L., Kharaka Y.K. \& Surdam R.C. (eds.) Relationship of organic matter and mineral diagenesis. Society of Economic Paleontologists and Mineralogists, Tulsa, 17:6-78. (Short Course Notes).

Gold P.B. 1987. Textures and geochemistry of authigenic albite from Miocene sandstones, Louisiana Gulf Coast. Journal of Sedimentary Petrology, 57:353-362.

Goldich S.S. 1938. A study in rock weathering. Journal of Geology, 46:17-58.

Gomes N.S. \& Vortisch W. 1991. Catadoluminescência: breve retrospectiva da técnica e exemplos de sua aplicação ao estudo de rochas sedimentares. Revista da Escola de Minas, Ouro Preto, 44:16-27. 
Hachiro J., Coutinho J.M.V., Riccomini C., Coimbra A.M., Fernandes L.A. 1994. O Astroblema de Piratiringa (São Paulo, Brasil). In: SBG, Simpósio sobre o Cretáceo do Brasil, 3. Rio Claro, Boletim, p. 93-96.

Matter A. \& Ramseyer K. 1985. Cathodoluminescence microscopy as a tool for provenance studies of sandstones. In: Zuffa G.G. (ed.) Provenance of Arenites. Dordrecht, D. Reidel Publishing Company, 148:191-211 (NATOASI Series C: Mathematical and Physical Sciences, 408p.)

Moore C.H. 1989. Carbonate diagenesis and porosity. Developments in Sedimentology, New York, Elsevier Science Publishers, 46, 338p.

Morad S. 1988. Diagenesis of titaniferous minerals in Jurassic sandstones from the Norwegian Sea. Sedimentary Geology, 57:17-40.

Morad S. 1991. Diagenesis of Clastic Sedimentary Rocks. Department of Mineralogy and Petrology, Institute of Geology, Uppsala University, 287p.

Morad S., Bergan M., Knarud R., Nystuem J.P. 1990. Albitization of detrital plagioclase in Triassic reservoir sandstones from the Snorre Field, Norwegian North Sea. Journal of Sedimentary Petrology, 60(3):411-425.

Morad S., Ketzer J.R.M.; De Ros, L.F. 2000. Spatial and temporal distribution of diagenetic alteration in siliciclastic rocks - implications for mass transfer in sedimentary basins. Sedimentology, 47:95-120.

Perry J.R. \& Hower J. 1972. Late-stage dehydration in deeply buried pelitic sediments. American Association of Petroleum Geologists Bulletin, 56:2013-2021.
Schmidt V. \& Mcdonald D.A. 1979. The role of secondary porosity in the course of sandstones diagenesis. In: Scholle P.A. \& Schluger P.R. (eds.) Aspects of Diagenesis. Tulsa, Society of Economic Paleontologists and Mineralogists Special Publication 26:175-208.

Saigal G.C., Morad S., Bjorlykke K., Egeberg P.K., Aagard P. 1988. Diagenetic albitization of detrital K-feldspar in Jurassic, Lower Cretaceous and Tertiary clastic reservoir rocks from offshore Norway: textures and origin. Journal of Sedimentary Petrology, 58:1003-1013.

Soares P.C. 1972. O limite glacial-pós-glacial do Grupo Tubarão no Estado de São Paulo. Anais da Academia Brasileira de Ciências, 44:333-341.

Stevaux J.C., Souza Filho E.E., Fúlfaro V.J. 1986. Trato deposicional da Formação Tatuí $(\mathrm{P})$ na área aflorante no nordeste da Bacia do Paraná, Estado de São Paulo. In: SBG, Congresso Brasileiro de Geologia, 34, Goiânia, Anais, 1:219-229.

Walker T.R. 1976. Diagenetic origin of continental Permian in west, central and south Europe. Proceedings of the NATO Advanced Study Institute, D. Reidel Pub. Co., Germany, p.240-282.

Zuffa G.G. 1985. Optical analyses of arenites: influence of methodology on compositional results. In: Zuffa G.G. (ed.) Provenance of Arenites. Dordrecht, D. Reidel Publishing Company, 148:165-189 (NATO-ASI Series C: Mathematical and Physical Sciences, 408p.).

Manuscrito ID 13685

Submetido em 23 de março de 2009 Aceito em 25 de fevereiro de 2010 